\title{
Self-Efficacy, Positive Future Outlook and School Burnout in Spanish Adolescents
}

\author{
África Martos Martínez ${ }^{1}{ }^{(0)}$, María del Mar Molero Jurado ${ }^{1, *} \mathbb{C}^{\mathbb{D}}$, María del Carmen Pérez-Fuentes ${ }^{1} \mathbb{D}$, \\ Ana Belén Barragán Martín ${ }^{1}$ (D) María del Mar Simón Márquez ${ }^{1} \mathbb{D}$, Begoña María Tortosa Martínez ${ }^{1}$, \\ Maria Sisto ${ }^{1}$ and José Jesús Gázquez Linares ${ }^{2}$ \\ 1 Department of Psychology, Faculty of Psychology, University of Almería, 04120 Almería, Spain; \\ amm521@ual.es (Á.M.M.); mpf421@ual.es (M.d.C.P.-F.); abm410@ual.es (A.B.B.M.); \\ msm112@ual.es (M.d.M.S.M.); btm172@ual.es (B.M.T.M.); ms168@ual.es (M.S.) \\ 2 Department of Psychology, Autonomous University of Chile, Providencia 7500000, Chile; jlinares@ual.es \\ * Correspondence: mmj130@ual.es; Tel.: +34-950-015-598
}

Citation: Martos Martínez, Á.; Molero Jurado, M.d.M.; Pérez-Fuentes, M.d.C.; Barragán Martín, A.B.; Simón Márquez, M.d.M.; Tortosa Martínez, B.M.; Sisto, M.; Gázquez Linares, J.J. Self-Efficacy, Positive Future Outlook and School Burnout in Spanish Adolescents. Sustainability 2021, 13, 4575. https:// doi.org/10.3390/su13084575

Academic Editor: Francisco Manuel Morales Rodríguez

Received: 4 March 2021

Accepted: 16 April 2021

Published: 20 April 2021

Publisher's Note: MDPI stays neutral with regard to jurisdictional claims in published maps and institutional affiliations.

Copyright: (c) 2021 by the authors. Licensee MDPI, Basel, Switzerland. This article is an open access article distributed under the terms and conditions of the Creative Commons Attribution (CC BY) license (https:// creativecommons.org/licenses/by/ $4.0 /)$.

\begin{abstract}
Background: Environmental and personal circumstances during adolescence cause changes affecting students, their wellbeing, performance, self-efficacy, motivation, and aspirations for the future. The objective of this study was to analyze the relationship between burnout, self-efficacy, and outlooks by student gender and age, and determine the influence of self-efficacy on burnout and outlooks for the future. Methods: The sample was made up of $1287 \mathrm{high}$ school students. The instruments used to collect data were The Control-Individual Protective Factors Index to evaluate self-efficacy, the Positive Outlook-Individual Protective Factors Index for aspirations, and finally, for burnout, the Maslach Burnout Inventory. Results: The results showed that the cynicism and exhaustion dimensions of burnout correlated negatively with self-efficacy and outlooks. On the contrary, the academic efficacy dimension showed a positive correlation with self-efficacy. In addition, the gender and age variables were related to burnout. Student self-efficacy was related to burnout and outlooks for the future, where youths with the highest levels of self-efficacy were those who had the most positive outlooks for the future and the least school burnout. Conclusions: Given the academic changes that impede commitment, self-efficacy, and outlooks for the future of youths, the design of intervention programs directed at improving adolescent self-efficacy would lower burnout levels and raise their outlooks.
\end{abstract}

Keywords: school burnout; self-efficacy; outlooks for future; adolescents

\section{Introduction}

Throughout students' education, a broad set of environmental and personal circumstances significantly affects them, especially during secondary education [1]. This stage of their education coincides with adolescence, a very important period of the individual's transition to adulthood characterized by emotional instability, high vulnerability, and influence by peers and media, such as social networking sites and internet [2-4]. Similarly, during this stage, the large amount of homework they have to do, and the need to clarify their interests to be able to make educational-career choices, can cause students stress and even lead to burnout and affect their education and future employment [5-8]. In this context, some students who do not have the essential strategies needed for facing the problems and demands of the school environment experience a loss of interest in schoolwork, high levels of demotivation, and even feelings of physical and mental exhaustion that can lead to their dropping out [9]. Such characteristics may favor the appearance of school burnout [10], a construct that has the following dimensions: (a) Emotional exhaustion, which refers to physical, emotional, and/or mental fatigue, (b) cynicism or disinterest in schoolwork, and (c) efficacy, related to aptitude for performing academic tasks. School burnout is related to high levels of stress and anxiety [1] and low scores in self-efficacy [11]. 
In addition, studies such as the one by Sepúlveda and Valdebenito [12] on building up aspirations in adolescents corroborate that students increasingly experience uncertainty in this decision-making stage. Their aspirations for employment are one of the most relevant predictors of academic results and future jobs, as they are understood as a complex disposition for planning and a sense of possibilities for the future that guides students in everyday tasks [13]. In this context, the environmental and personal variables that appear during their education have an important role in students' adaptation in the school, and can influence them in matters such as wellbeing, performance [9,10,14-16], self-efficacy [17,18], motivation [19], and adolescent aspirations for the future [20].

\subsection{Relationship Between Burnout, Self-Efficacy, and Outlooks for the Future}

According to León-Rubio et al. [21], self-efficacy determines the effort students make, providing them with an active role, preventing stress and exhaustion, and arbitrating the relationship between exhaustion and low performance. It is therefore a burnout preventive factor, as the beliefs one has about his/her own efficacy reduce the effects of stressful situations. This may be because efficacious students do not associate academic demands with stress, but with overcoming difficulties. In this sense, these authors found that selfefficacy was a moderator of burnout, since having high scores in self-efficacy lowered the probability of developing the syndrome. However, there is some controversy about this, as some results show that the relationship between these two variables is weak [22]. It should also be mentioned that student aspirations affect their educational-career choices, which are constructed during their education [8].

Therefore, self-efficacy is a personal competency that enables students to cope with stressful situations or complete a task, becoming an important factor in psychoeducational research in recent decades [23-26]. This is because of its relationship with educational variables, with students' academic results and their motivation [27], satisfaction, stress, and burnout $[28,29]$. Thus, self-efficacy is closely related to future aspirations and burnout, since higher beliefs in self-efficacy show a relationship with lower burnout scores. That is, less self-efficacy is correlated with higher scores in burnout [30]. Like those with low self-efficacy, they accentuate their own deficiencies, and their aspirations are lowered [31]. In light of the evidence reviewed, the hypothesis posed was that student self-efficacy would be related to burnout and aspirations for the future, such that youths with higher self-efficacy would have a more positive future outlook and less school burnout [32-37].

\subsection{Differences by Gender and Age}

In beginning a discussion of adolescent gender, some authors have provided evidence that there are differences in burnout dimensions, where girls have higher levels of school burnout $[6,20,38]$. However, even though girls are more prone to burnout, they also usually devote more time to schoolwork [39]. Furthermore, González, Portolés, Muñoz, and López [40] corroborated that boys have higher self-efficacy and vigor than girls. On the contrary, Portolés and González [41] stated that girls have higher scores in academic selfefficacy. Thus, some authors think these contradictory findings are due to the influence of characteristics of the students, and that it is important that these differences be studied [21] Thus, another hypothesis was proposed, expecting to find significant gender differences in school burnout, self-efficacy, and aspirations for the future.

Attention was also given to burnout with respect to age. Widlund et al. [20] found there were significant differences between younger adolescents and those who were in late adolescence. However, Sagone et al. [17] found no differences between gender or age in scores on commitment and the self-efficacy factor of burnout, although competence and aspirations were higher in later adolescence than in early and middle adolescence. On the contrary, the findings of Janko and Smeds [30] verified that aspirations of adolescents were not significantly different by age, while the study by Ochoa and Diez-Martínez [42] stated that future aspirations appeared mainly in primary education (6-12 years), diminishing with age and grade level. Continuing with this affirmation, García-Castro and 
Bartolucci [43] corroborated that at older ages, the possibility of dropping out of school increased, and therefore, future outlook was also lower. In view of this controversy, the next hypothesis posed was that factors such as age would be positively related to burnout and negatively to self-efficacy and aspirations for the future.

\subsection{The Present Study}

The purpose of this study was to analyze the relationship between school burnout, selfefficacy, and aspirations for the future in relation to gender and age and determine whether there are any differences in burnout and outlook for the future by level of self-efficacy.

Therefore, based on the empirical evidence, the following hypotheses were formulated:

Hypothesis 1 (H1). There are statistically significant gender differences in school burnout, selfefficacy, and outlooks for the future.

Hypothesis 2 (H2). Age shows a positive association with burnout and negative with self-efficacy and outlooks.

Hypothesis 3 (H3). Self-efficacy is related to burnout and outlooks for the future, such that students who show higher levels of self-efficacy also have more positive outlooks for the future and lower school burnout.

\section{Materials and Methods}

\subsection{Participants}

The sample was made up of 1287 public high school students in the province of Almeria (Spain), aged 14 to 18 with a mean age of $15.11(S D=0.91)$. The gender distribution was $47.09 \%(n=606)$ boys and $52.91 \%(n=681)$ girls, with mean ages of $15.12(S D=0.94)$ and $15.10(S D=0.88)$, respectively. The grade distribution was $55 \%(n=707)$ in 11 th grade and $45 \%(n=577)$ in 12 th grade.

\subsection{Instruments}

An ad hoc questionnaire was prepared for collection of sociodemographic data (age, gender, grade).

The Control-Individual Protective Factors Index [44] was employed for the evaluation of self-efficacy. This scale consists of 13 items with four Likert-type answer choices (where 1 equals "completely disagree" and 4 "completely agree"), which are grouped in two dimensions: Self-efficacy and self-control. The reliability found for the self-efficacy dimension used in this study was $\alpha=0.59$ and $\alpha=0.62$ for the self-control scale.

Aspirations were evaluated with the Positive Outlook-Individual Protective Factors Index [44]. Made up of six items, this scale measures positive future outlook. The answers are rated on a Likert-type scale from 1 ("completely disagree") to 4 ("completely agree"). The Cronbach's alpha reliability coefficient in this study was $\alpha=0.60$.

School burnout was evaluated with the Maslach Burnout Inventory (MBI) [45] adapted for students [46]. It has 15 items with answer choices on a six-point Likert-type scale (from "never" to "always/every day"), on three scales: Exhaustion (feeling of not being able to do more at school, finding oneself physically and emotionally exhausted), cynicism (devaluation, criticism, and loss of interest as an attitude toward study), and efficacy (feelings of personal realization in study). The reliability reported by the Cronbach's alpha for the scales on the questionnaire was $\alpha=0.85$ for exhaustion, $\alpha=0.81$ for cynicism, and $\alpha=0.80$ for efficacy.

\subsection{Procedure}

Before starting with data collection, the principals of the schools were contacted, and a meeting was arranged to inform them about the objectives of the study and guarantee confidential data processing. After scheduling the test sessions, two members of the 
research team went to the schools to administer the questionnaires. The tests were filled out in the usual classroom assigned to each group in the presence of the teacher in charge. At the beginning of the session, before completing the questionnaires, the students were given the appropriate instructions and time to ask any questions they might have, and ensured the anonymity of their answers, respecting their privacy during statistical processing. The students took the tests anonymously and individually in an average time estimated at 25-30 min. The study was approved by the University of Almeria Bioethics Committee (Ref: UALBIO2018/015).

\subsection{Data Analysis}

The statistical analysis was carried out with SPSS version 24.0 [47]. First, the descriptive parameters were found by descriptive and frequency analyses. In addition, to examine any statistically significant gender differences in the school burnout factors, outlooks, and self-efficacy, the Student's $t$-test was applied and Cohen's $d$ for effect size. The Pearson's correlation was used to determine the relationship between age, perceived self-efficacy, school burnout factors, and outlooks for the future. Finally, to compare the differences in the burnout factors and outlooks of students on different points on the self-efficacy continuum, they were divided into three groups following previous studies [25]. In this case, this was done by visual grouping based on the cases explored. Thus, participants were distributed by low self-efficacy (those students scoring below 24), medium self-efficacy (from 24 to 26 points on the scale), and high self-efficacy (over 26). After stratifying the sample by self-efficacy, an ANOVA was done to find out whether there were differences between the groups in burnout and outlooks for the future. Welch's F-test [48] was computed, because it is recommended for unequal sample sizes ( $n=508, n=430, n=338)$ and when the assumption of homogeneity of variances for one-way ANOVA is violated (in this case, the Levene's test revealed significance in two of the four dependent variables: Exhaustion $p<0.01$; Cynicism $p<0.05$; Efficacy $p=0.399$; Positive Future Outlook $p=0.70$ ).

\section{Results}

\subsection{Self-Efficacy, Outlooks for the Future, and School Burnout by Gender}

Table 1 shows the results of means found boys and girls in the three dimensions of burnout, future outlook, and self-efficacy and self-control. As observed, girls had significantly higher mean scores in the exhaustion factor of burnout $\left(t_{(1285)}=-4.42 ; p<0.001 ; d\right.$ $=0.25)$ and in self-efficacy $\left(t_{(1285)}=-3.26 ; p<0.01 ; d=0.18\right)$. Meanwhile, in the cynicism factor of burnout, it was the boys who had significantly higher scores $\left(t_{(1285)}=2.29 ; p<0.01\right.$; $d=0.13)$.

Table 1. Self-efficacy, outlooks for the future, and engagement. Descriptive statistics and $t$-test by gender.

\begin{tabular}{|c|c|c|c|c|c|c|c|c|c|}
\hline \multirow{3}{*}{\multicolumn{2}{|c|}{ Variables }} & \multicolumn{6}{|c|}{ Gender } & \multirow{3}{*}{$t$} & \multirow{3}{*}{$p$} \\
\hline & & \multicolumn{3}{|c|}{ Boys } & \multicolumn{3}{|c|}{ Girls } & & \\
\hline & & $n$ & $M$ & $S D$ & $n$ & $M$ & $S D$ & & \\
\hline \multirow{3}{*}{ School Burnout } & Exhaustion & 606 & 17.89 & 7.59 & 681 & 19.70 & 7.02 & $-4.42^{* *}$ & 0.000 \\
\hline & Cynicism & 606 & 10.88 & 6.35 & 681 & 9.79 & 6.60 & $2.29 *$ & 0.003 \\
\hline & Efficacy & 606 & 22.83 & 7.29 & 681 & 23.58 & 6.76 & -1.90 & 0.058 \\
\hline \multicolumn{2}{|c|}{ Positive future outlook } & 606 & 18.70 & 2.99 & 681 & 18.50 & 2.79 & 1.20 & 0.229 \\
\hline \multirow{2}{*}{ Self-Efficacy } & Self-efficacy & 606 & 24.45 & 2.71 & 681 & 24.91 & 2.29 & $-3.26^{*}$ & 0.001 \\
\hline & Self-control & 606 & 17.84 & 3.28 & 681 & 18.03 & 3.24 & -1.00 & 0.314 \\
\hline
\end{tabular}




\subsection{Relationship Between Age, Self-Efficacy, Future Outlooks, and School Burnout in Adolescents}

Table 2 shows the results for the relationship between age, burnout, outlooks for the future, and self-efficacy in the high school students. Age was not related to self-efficacy or positive future outlook, so the older age of high school students did not seem to be related to feelings of general efficacy or outlooks for the future. On the contrary, a positive relationship was found with the exhaustion $(r=0.07 ; p<0.01)$ and cynicism $(r=0.11$; $p<0.001)$ factors of burnout, and negative with feeling of academic efficacy $(r=-0.08$; $p<0.01)$. Nevertheless, the strength of the relationship was low.

Table 2. Correlation matrix for age, burnout, self-efficacy, cynicism, and outlook for the future.

\begin{tabular}{ccccccc}
\hline Variable & Exhaustion & Cynicism & Efficacy & $\begin{array}{c}\text { Self- } \\
\text { Efficacy }\end{array}$ & $\begin{array}{c}\text { Self- } \\
\text { Control }\end{array}$ & Outlook \\
\hline Age & $0.07^{*}$ & $0.10^{* *}$ & $-0.08^{*}$ & 0.00 & -0.03 & -0.02 \\
Exhaustion & - & $0.57^{* *}$ & $-0.12^{* *}$ & $-0.08^{*}$ & $-0.26^{* *}$ & $-0.20^{* *}$ \\
Cynicism & - & - & $-0.29^{* *}$ & $-0.15^{* *}$ & $-0.31^{* *}$ & $-0.26^{* *}$ \\
Efficacy & - & - & - & $0.20^{* *}$ & $0.15^{* *}$ & $0.28^{* *}$ \\
Self-efficacy & - & - & - & - & $-17^{* *}$ & $0.31^{* *}$ \\
Self-control & - & - & - & - & - & $0.22^{* *}$ \\
${ }^{* p<0.01 ; * *} p<0.001$. & & & & & &
\end{tabular}

Furthermore, the burnout exhaustion subscale was negatively associated with the self-efficacy $(r=-0.08 ; p<0.01)$ and self-control $(r=-0.27 ; p<0.001)$ scales, as well as positive future outlook $(r=-0.20 ; p<0.001)$. The burnout cynicism factor was also significantly negatively associated with self-efficacy $(r=-0.16 ; p<0.001)$, self-control $(r=-0.32$; $p<0.001)$, and positive future outlook $(r=-0.26 ; p<0.001)$. Therefore, adolescents feeling emotionally exhausted by studies and devaluing them are related to feeling less efficacy and personal control, and a less-positive outlook. On the other hand, the academic efficacy burnout factor showed a positive relationship with self-efficacy $(r=0.21 ; p<0.001)$ and self-control $(r=0.16 ; p<0.001)$, and also positive future outlook $(r=0.28 ; p<0.001)$. Concerning the relationship between the self-efficacy and positive outlook factors, a significantly positive correlation was found between the two self-efficacy factors, that is, with self-control $(r=0.31 ; p<0.001)$ and self-efficacy $(r=0.22 ; p<0.001)$. Therefore, higher self-efficacy is associated with youths having more promising future goals and outlooks.

\subsection{Differences in Burnout and Positive Future Outlook by Level of Self-Efficacy}

Students were grouped into low, medium, and high by the self-efficacy levels. After that, the differences in positive future outlook and burnout components were analyzed by these groups, also entering gender as a covariate, since the gender effect on the grouping factor was found in Table 1 (that is, self-efficacy).

The homogeneity of covariance was examined by Box's $M$-test and the null hypothesis of data fit was accepted $\left(M_{B o x}=24.78 ; F_{(20,4714302.127)}=1.23 ; p>0.05\right)$. The multivariate comparison showed that there were no significant between-group differences $\left(\lambda_{\text {Wilks }}=0.98\right.$; $\left.F_{(8,2534)}=1.93 ; p>0.05\right)$, so gender had no effect on the dependent variables.

In addition, analyzing the relationship for the dependent variables mentioned above individually (Figure 1), significant differences were found between self-efficacy groups in the Academic Efficacy factor $\left(F_{(2,1275)}=29.32 ; p<0.001\right)$. Post hoc comparisons showed that the participants with low self-efficacy had a significantly lower score than the medium self-efficacy group or than youths with high self-efficacy. Significant differences were also found between self-efficacy groups in burnout's exhaustion $\left(F_{(2,1275)}=5.06 ; p<0.01\right)$ and cynicism $\left(F_{(2,1275)}=12.36 ; p<0.001\right)$. Specifically, differences were found between high self-efficacy and medium and low self-efficacy, but not between the last two. Thus, youths who showed low self-efficacy are those who were the most exhausted and had a more cynical attitude toward study, followed by those who had medium self-efficacy. Those who had high self-efficacy were the least affected by these school burnout factors. Along 
the same line, in Positive Future Outlook, significant differences were detected among the three groups $\left(F_{(2,1275)}=51.53 ; p<0.001\right)$, where adolescents in the high self-efficacy group showed a more positive outlook than youths with medium self-efficacy or, in turn, than the low self-efficacy group.

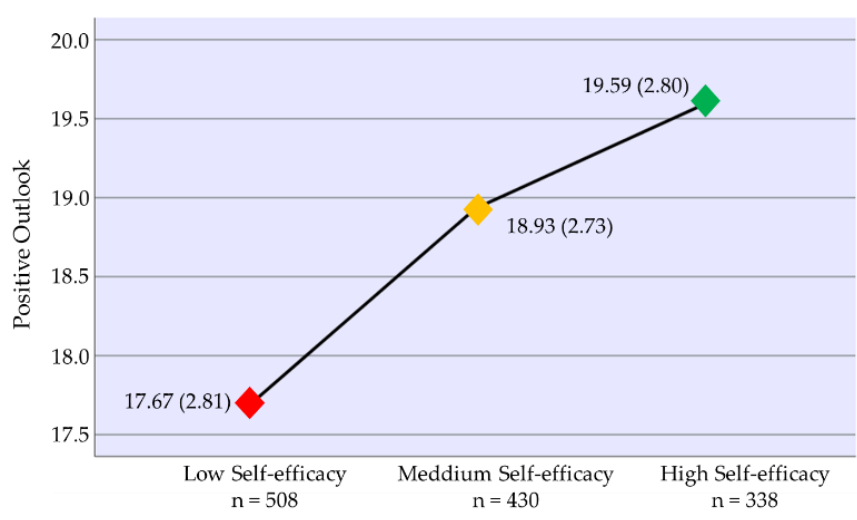

(a)

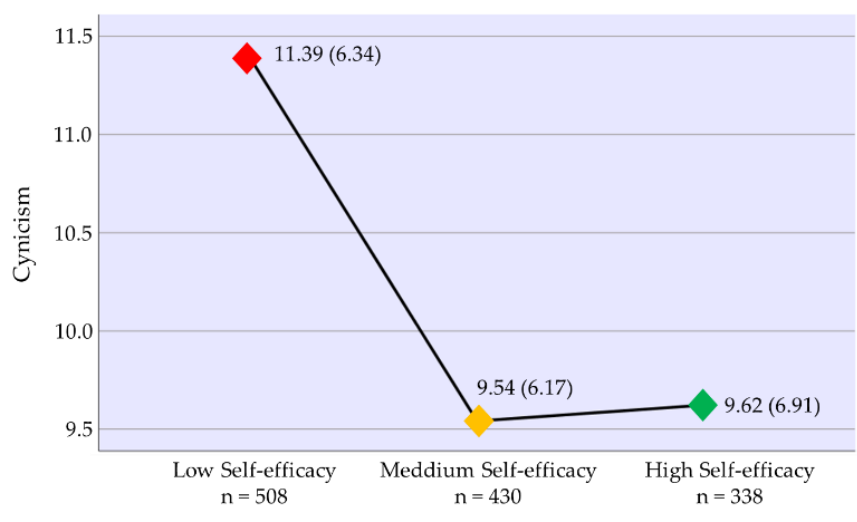

(c)

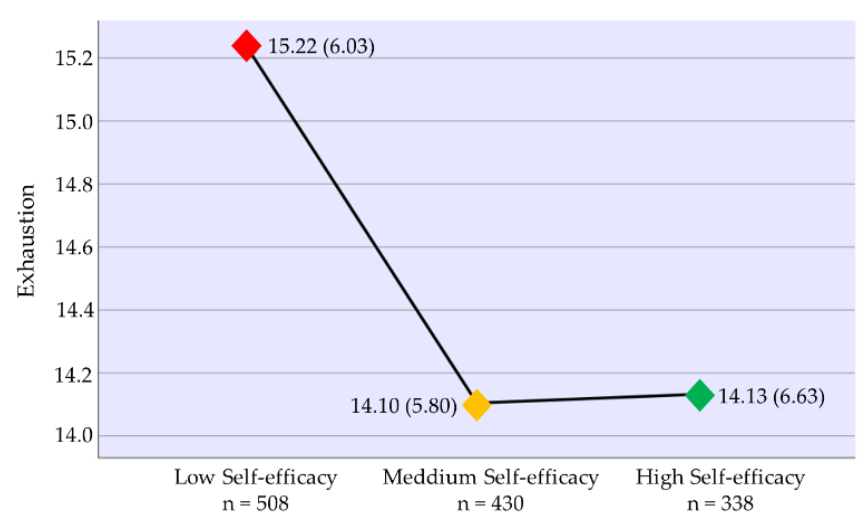

(b)

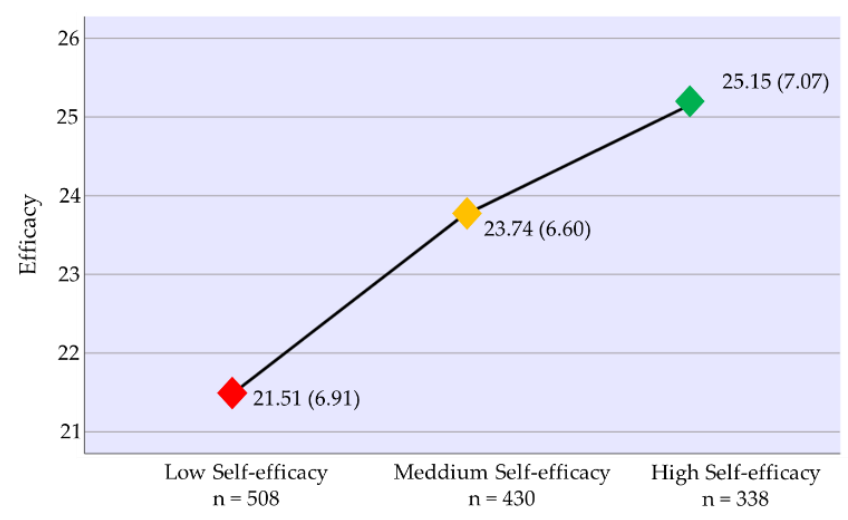

(d)

Figure 1. Mean scores in burnout and positive outlook by level of self-efficacy. Note: M(SD). (a) Positive Outlook; (b) Exhaustion; (c) Cynicism; (d) Efficacy.

\section{Discussion}

High school may mean strong environmental, personal, and academic changes for adolescents, which impede commitment and classroom performance [1-3,5].

This descriptive cross-sectional study analyzed differences between school burnout, self-efficacy, and future outlooks with respect to student gender and age. In addition, the influence of self-efficacy on student burnout and outlooks for the future were also studied. Based on the literature stating that there are differences between girls and boys insofar as burnout dimensions, self-efficacy and future aspirations are concerned [20,40,41]. Moreover, there were statistically significant gender differences in school burnout, selfefficacy, and outlooks for the future, since part of these results coincide with previous studies, such as those by González et al. [40] and González-Cabanach et al. [25], which showed that boys have higher self-efficacy and vigor than girls, the first hypothesis posed.

The second hypothesis of this study was also confirmed. As found elsewhere $[17,20]$, factors such as age showed a positive association with burnout and negative with aspirations. This was verified by focusing on the age and gender of the adolescents, corroborating that there is a negative association with self-efficacy. It was also verified that outlooks of adolescents had no significant relationship with their age [30]. This may be because the study sample was homogeneous, as the participant age range was not wide enough to show differences in 
maturity or developmental change. It would therefore be advisable to continue enquiry in this respect.

The last hypothesis posed referred to the relationship between self-efficacy shown by the students with burnout and future outlooks. Self-efficacy induces to stable personal competence for coping with potentially stressful situations $[23,41]$. This involves a relationship with a diversity of educational variables, with the scholastic results of students, with their motivation [27], with satisfaction, and with stress and burnout levels [29]. Thus, youths who show higher self-efficacy have a more positive outlook for the future and less school burnout [30].

Although with some limitations, these results show important theoretical and practical implications. It shows a valid theoretical justification for the contradictory findings on the relationship between self-efficacy, future outlooks, and academic burnout in previous studies [21]. In particular, the results of this study confirm the idea that self-efficacy is related to academic burnout and future outlook. Furthermore, from a practical perspective, it was found that the promotion of self-efficacy could be an effective strategy for reducing the stress that some students are subjected to and favor their perspectives for the future [21]. Some limitations should be mentioned. In the first place, the scant bibliography found analyzing the relationships between the high school student variables undertaken in this study, hindering construction of sufficient theoretical argument to back its findings. Therefore, future research should delve further into the relationship between adolescent burnout, self-efficacy, and outlooks for the future. Furthermore, contextual factors that could have been affecting the participants, such as exposure to stressful situations, were not taken into consideration, so future research should also include stress due to its importance in developing burnout. In addition, the reliability indices of some of the scales (for example positive outlook) were relatively low. Finally, the sample was taken from high schools and did not address adolescents with school absenteeism. Therefore, following studies should use sampling techniques that allow them access to this sector of the population.

\section{Conclusions}

High school can involve enormous personal, social, and academic changes impeding adolescent commitment, self-efficacy, classroom performance, and outlook for the future. The strong presence of school burnout in high schools is of severe social concern, due to the effects it can cause on educational variables affecting youths. Therefore, knowing the influence of individual, sociodemographic, and psychological variables, such as selfefficacy, in the development of this syndrome and in promoting future aspirations, makes it a subject of vital importance. This particular study demonstrated that age and gender marked differences in burnout levels, contrary to self-efficacy and outlooks, in which age was not an influential factor. It should also be mentioned that self-efficacy is a personal competency that is related to future outlooks, stress, and burnout, demonstrating that lower self-efficacy is correlated with higher scores in exhaustion, and those subjects who show low self-efficacy have lower future outlooks.

Adolescents' main current and future outlooks are organized, planning tasks-goalsplans, after changes affecting their academic and employment environment, aesthetic and moral values, personal integration, and self-development. These results showed that self-efficacy is higher in adolescents with lower burnout and more favorable aspirations. Therefore, it would be advisable for science to study further the relationship between self-efficacy, future outlooks, and school burnout, and thereby also, its negative effects, improving students' aspirations.

Author Contributions: Conceptualization, Á.M.M., M.d.M.M.J., M.d.C.P.-F., A.B.B.M., M.d.M.S.M. and M.S.; data curation, Á.M.M., M.d.M.M.J. and M.d.C.P.-F.; formal analysis, Á.M.M., M.d.M.M.J., M.d.C.P.-F. and M.S.; investigation, Á.M.M., M.d.M.M.J., M.d.C.P.-F., A.B.B.M., M.d.M.S.M., M.S. and J.J.G.L.; methodology, Á.M.M., M.d.M.M.J., M.d.C.P.-F., A.B.B.M., M.d.M.S.M., M.S. and J.J.G.L.; resources, A.B.B.M., M.d.M.S.M. and M.S.; writing—original draft, Á.M.M., M.d.M.M.J., M.d.C.P.-F. 
and B.M.T.M.; writing-review and editing, A.B.B.M., M.d.M.S.M., M.S. and J.J.G.L. All authors have read and agreed to the published version of the manuscript.

Funding: This research received no external funding.

Institutional Review Board Statement: The study was conducted according to the guidelines of the Declaration of Helsinki, and approved by the Ethics Committee of the University of Almeria (Ref: UALBIO2018/015).

Informed Consent Statement: Informed consent was obtained from all subjects involved in the study.

Data Availability Statement: The data that support the findings of this study are available from the corresponding author upon reasonable request.

Acknowledgments: The present study was undertaken in collaboration with the "Peer violence and alcohol and tobacco use in Secondary Education program: an augmented reality program for detection and intervention" (Reference: EDU2017-88139-R), funded by the State Research Program, Development and Innovation Oriented to the Challenges of Society, within the framework of the State Plan for Scientific and Technical Research and Innovation, and co-financing with Structural Funds of the European Union.

Conflicts of Interest: The authors declare no conflict of interest.

\section{References}

1. Usán, P.; Salavera, C.; Domper, E. How are the variables of burnout, engagement and academic self-efficacy interrelated? A study with school adolescents. Rev. Electron. Interuniv. Form. Profr. 2018, 21, 141-153.

2. Bewick, B.; Koutsopoulou, G.; Miles, J.; Slaa, E.; Barkham, M. Changes in undergraduate students' psychological well-being as they progress through university. Stud. High. Educ. 2010, 35, 633-645. [CrossRef]

3. Booker, J.A.; Dunsmore, J.C. Affective social competence in adolescence: Current findings and future directions. Soc. Dev. 2017, 26, 3-20. [CrossRef]

4. Gómez-Fraguela, J.A.; Fernández, N.; Romero, E.; Luengo, A. El botellón y el consumo de alcohol y otras drogas en la juventud the bottle and the consumption of alcohol and other drugs in youth. Trastor. Adict. 2008, 20, 211-217.

5. Gaete, V. Desarrollo psicosocial del adolescente [Psychosocial development of the adolescent]. Rev. Chil. Pediatr. 2015, 86, 436-443. [CrossRef] [PubMed]

6. Salmera-Aro, K.; Tynkkynen, L. Gendered pathways in school burnout among adolescents. J. Adolesc. 2012, 35, 929-939. [CrossRef] [PubMed]

7. Salmela-Aro, K. Dark and bright sides of thriving-School burnout and engagement in the Finnish context. Eur. J. Dev. Psychol. 2017, 14, 337-349. [CrossRef]

8. Sepúlveda, L. Aspirations y proyectos de future de jóvenes estudiantes secundarios en Chile: El spirte familiar y su influencia en las decisiones educativo-laborales [Aspirations and future projects of young high school students in Chile: The family spirit and its influence on educational-labor decisions]. Educ. Em Rev. 2017, 33, e158258.

9. Musitu, G.; Giménez, T.; Murgui, S. Funcionamiento familiar, autoestima y consumo de sustancias en adolescentes: Un modelo de mediación [Family functioning, self-esteem and substance use in adolescents: A mediation model]. Salud Pública México 2012, 49, 3-10. [CrossRef]

10. Usán, P.; Salavera, C.; Mejías, J.J. Relationship between Emotional Intelligence, Academic Burnout and School Performance in Adolescent Students. Ces Psicol. 2020, 13, 125-139.

11. Rodriguez-García, A.M.; Sola-Martínez, T.; Fernández-Cruz, M. Impact of Burnout on the professional development of professors. A review of research. Rev. Electron. Interuniv. Form. Profr. 2017, 20, 161-178.

12. Sepúlveda, L.; Valdebenito, M.J. Las cosas claras? Aspirations de future y proyecto educativo laboral de jóvenes estudiantes secundarios [Clear things? Aspirations of the future and educational project for young high school students]. Estud. Pedagógicos 2014, 40, 243-261. [CrossRef]

13. Sellar, S.; Gale, T.; Parker, S. Appreciating aspirations in Australian higher education. Camb. J. Educ. 2011, 41, 37-52. [CrossRef]

14. García-Hermoso, A.; Oriol-Granado, X.; Correa-Bautista, J.E.; Ramírez-Vélez, R. Association between bullying victimization and physical fitness among children and adolescents. Int. J. Clin. Health Psychol. 2019, 19, 134-140. [CrossRef]

15. Martínez-Alvarado, J.R.; Guillén, F.; Aguiar, L.H.; Magallanes, A.G.; Fernández, P.F.; Ali, A. Analysis of the psychometric properties of the Athlete Burnout Questionnaire (ABQ) in Mexican athletes. An. Psicol. 2019, 35, 341-349. [CrossRef]

16. Maganto, C.; Peris, M.; Sánchez, R. Psychological well-being in adolescence: Associated and predictive psychological variables. Eur. J. Psychol. Educ. 2019, 12, 139-151. [CrossRef]

17. Sagone, E.; De Caroli, E.; Falanga, R.; Indiana, M.L. Resilience and perceived self-efficacy in life skills from early to late adolescence. Intl. J. Adolesc. Youth 2020, 25, 882-890. [CrossRef]

18. Sagone, E.; Indiana, M.L. The relationship of positive affect with resilience and self-efficacy in life skills in Italian adolescents. Psychology 2017, 8, 2226-2239. [CrossRef] 
19. Symonds, J.; Schoon, I.; Eccles, J.; Salmela-Aro, K. The development of motivation and amotivation to study and work across age-graded transitions in adolescence and young adulthood. J. Youth Adolesc. 2019, 48, 1131-1145. [CrossRef]

20. Widlund, A.; Tuominen, H.; Korhonen, J. Academic well-being, mathematics performance, and educational aspirations in lower secondary education: Changes within a school year. Front. Psychol. 2018, 9, 297. [CrossRef]

21. León-Rubio, J.M.; Cantero, F.J.; León-Pérez, J.M. Diferencias del rol desempeñado por la autoeficacia en el burnout percibido por el personal universitario en función de las condiciones de trabajo. An. Psicol. 2011, 27, 518-526.

22. Vancouver, J.B.; More, K.M.; Yoder, R.J. Self-efficacy and resource allocation: Support for a nonmonotonic discontinuous model. J. Appl. Psychol. 2008, 93, 35-47. [CrossRef]

23. Bandura, A. Self-Efficacy: Toward a unifying theory of behavioral change. Psychol. Rev. 1977, 84, 191-215. [CrossRef] [PubMed]

24. Duffin, L.C.; French, B.F.; Patrick, H. The Teachers' Sense of Efficacy Scale: Confirming the factor structure with beginning pre-service teachers. Teach. Teach. Educ. 2012, 28, 827-834. [CrossRef]

25. González-Cabanach, R.; Valle, A.; Freire, C.; Ferradás, M.Y. Relaciones entre la self-efficacy percibida y el bienestar psicológico en estudiantes universitarios. Rev. Mex. Psicol. 2012, 29, 40-48.

26. Liu, T.; Chen, X.; Liu, M.; Zhang, Y.; Xin, T.; Wang, Y. The effects of children's self-educational aspiration and self-efficacy on mathematics achievement: A moderated chained mediation model. Ann. Psychol. 2020, 36, 262-270.

27. Caprara, G.V.; Barbaranelli, C.; Steca, P.; Malone, P.S. Teachers self-efficacy as determinants of job satisfaction and students' academic achievement: A study at the school level. J. Sch. Psychol. 2006, 44, 473-490. [CrossRef]

28. Castellano, E.; Muñoz-Navarro, R.; Sol, M.; Spontón, C.; Medrano, L.A. Cognitive processes of emotional regulation, burnout and work engagement. Psicothema 2019, 31, 73-80.

29. Skaalvik, E.M.; Skaalvik, S. Teacher self-efficacy and teacher burnout: A study of relations. Teach. Teach. Edu. 2010, 26, 1059-1069. [CrossRef]

30. Janko, M.R.; Smeds, M.R. Burnout, depression, perceived stress, and self-efficacy in vascular surgery trainees. J. Vasc. Surg. 2019, 69, 1233-1242. [CrossRef]

31. Galleguillos-Herrera, P.; Olmedo-Moreno, E. Academic self-efficacy and motivation: A measurement for the achievement of school objectives. Eur. J. Investig. Health Psychol. Educ. 2019, 9, 119-135. [CrossRef]

32. Palacio, S.; Caballero, C.; González, O.; Gravini, M.; Contreras, K. Relación del burnout y las estrategias de afrontamiento con el rendimiento académico en estudiantes universitarios. Univ. Psychol. 2012, 11, 178-186.

33. Martos, Á.; Pérez-Fuentes, M.C.; Molero, M.M.; Gázquez, J.J.; Simón, M.M.; Barragán, A.B. Burnout y engagement en estudiantes de Ciencias de la Salud. Eur. J. Investig. Health Psychol. Educ. 2018, 8, 23-36. [CrossRef]

34. Pérez-Fuentes, M.C.; Molero, M.M.; Simón, M.M.; Oropesa, N.F.; Gázquez, J.J. Validation of the Maslach burnout inventorystudent survey in Spanish adolescents. Psicothema 2020, 32, 444-451.

35. Pérez-Fuentes, M.C.; Molero-Jurado, M.M.; Gázquez-Linares, J.J.; Simón-Márquez, M.M. Analysis of burnout predictors in nursing: Risk and protective psychological factors. Eur. J. Psychol. Appl. Leg. Context 2019, 11, 33-40. [CrossRef]

36. Salmela-Aro, K.; Upadyaya, K. School engagement and school burnout profiles during high school. The role of socio-emotional skills. Eur. J. Dev. Psychol. 2020, 1, 1-25. [CrossRef]

37. Vizoso-Gómez, C.; Arias-Gundín, O. Resiliencia, optimismo y burnout académico en estudiantes universitarios [Resilience, optimism and academic burnout in university students]. Eur. J. Educ. Psychol. 2018, 11, 47-59. [CrossRef]

38. Salmela-Aro, K.; Kiuru, N.; Nurmi, J.-E. The role of educational track in adolescents' school burnout: A longitudinal study. Br. J. Educ. Psychol. 2008, 78, 663-689. [CrossRef] [PubMed]

39. Salmela-Aro, K.; Upadyaya, K. The schoolwork engagement inventory: Energy, dedication, and absorption (EDA). Eur. J. Psychol. Assess. 2012, 28, 60-67. [CrossRef]

40. González, J.; Portolés, A.; Muñoz, A.J.; López, C. Perfeccionismo, engagement y actividad física. Influencias en el rendimiento académico. In Investigación en el Ámbito Escolar: Un Acercamiento Multidimensional a las Variables Psicológicas y Educativas; Gázquez, J.J., Molero, M.M., Pérez-Fuentes, M.C., Simón, M.M., Barragán, A.B., Martos, A., Eds.; ASUNIVEP: Almería, Spain, 2016; pp. 169-178.

41. Portolés, A.; González, J. Rendimiento académico y correspondencias con indicadores de salud física y psicológica [Academic performance and correspondence with indicators of physical and psychological health]. Sportis 2015, 1, 164-181. [CrossRef]

42. Ochoa, A.; Diez-Martínez, E. Relación entre Primera y Segunda Aspiración Ocupacional: Vocación o Educación? REMO 2011, 8, 51-59.

43. García-Castro, G.; Bartolucci, J. Aspiraciones educativas y logro académico. Un estudio de caso sobre características y condiciones sociales de los estudiantes de la UAM. Rev. Mex. De Investig. Educ. 2007, 12, 1267-1288.

44. Phillips, J.; Springer, F. Extended National Youth Sports Program 1991-1992 Evaluation Highlights, Part Two: Individual Protective Factors Index (IPFI) and Risk Assessment Study; Report prepared for the National Collegiate Athletic Association; EMT Associates: Sacramento, CA, USA, 1992.

45. Maslach, C.; Jackson, S.E. The Maslach Burnout Inventory; Consulting Psychologist Press: Palo Alto, CA, USA, 1981.

46. Schaufeli, W.B.; Martinez, I.M.; Marques, A.; Salanova, M.; Bakker, A.B. Burnout and engagement in university students. A Cross National Study. J. Cross Cult. Psychol. 2002, 33, 464-481. [CrossRef] 
47. IBM Corp. IBM SPSS Statistics for Windows (Version 24.0); IBM Corp: Armonk, NY, USA, 2016.

48. Delacre, M.; Leys, C.; Mora, Y.L.; Lakens, D. Taking Parametric Assumptions Seriously: Arguments for the Use of Welch's F-test instead of the Classical F-test in One-Way ANOVA. Int. Rev. Soc. Psychol. 2019, 32, 13. [CrossRef] 